\section{Relações econômicas internacionais: o Brasil na globalização}

\section{Paulo Roberto de Almeida}

Professor no Centro Universitário de Brasília (Uniceub); Diretor do Instituto de Pesquisa de Relações Internacionais, IPRI-Funag/MRE. Email: pralmeida@me.com

Texto proferido durante Aula Magna do Programa de Pós-Graduação em Ciências Jurídicas da UFPB do semestre 2018.1 


\title{
Relações econômicas internacionais: o Brasil na globalização
}

\author{
Paulo Roberto de Almeida
}

\section{RELAÇÕES INTERNACIONAIS, POLÍTICA INTERNACIONAL, POLÍTICA EXTERNA E DIPLOMACIA}

Numa classificação das liberdades econômicas, a situação do Brasil, em escala mundial, bem que poderia ser menos humilhante. Segundo o relatório de 2017 do Fraser Institute, o Brasil ocupa um medíocre $137^{\circ}$ lugar entre 159 países, atrás de todos os demais parceiros do Brics, grupo no qual duas democracias de baixa qualidade, Índia e África do Sul, estão num mesmo 95º lugar, e duas autocracias, Rússia e China, se situam respectivamente nas posições $100^{\circ}$ e $112^{\circ}$, todas no terceiro quartil. Mesmo na região, nossa posição é frustrante, acima apenas da Argentina (os dados são de 2015) e da Venezuela, esta em último lugar (Cuba e Coreia do Norte não figuram). O Chile, que já entrou na OCDE, ocupa o 15º lugar, à frente de vários países desenvolvidos.

Entre as vinte maiores economias do mundo, o G-20, o Brasil registra o menor coeficiente de abertura externa; ou seja, é um país notoriamente fechado ao comércio exterior. Mesmo recebendo um volume apreciável de investimentos estrangeiros, esses fluxos, quando confrontados ao tamanho de sua economia, representam 
Relações econômicas internacionais: o Brasil na globalização

uma proporção muito pequena do PIB. Dados objetivos revelam: os países de maior renda são os mais abertos aos fluxos internacionais de comércio e investimentos; as economias mais prósperas são as de maior inovação, e isso se consegue adquirindo capacidades internas a partir de possibilidades externas. A política externa é também política econômica.

Sob qualquer critério que se considere, relações internacionais constituem uma parte incontornável da situação doméstica, e elas serão tão mais relevantes se assumidas conscientemente, deliberadamente, ativamente, não de modo tímido, defensivo ou introvertido. Países voltados para objetivos de crescimento e de desenvolvimento, incorporam a política externa e o instrumento da diplomacia ao conjunto das políticas públicas de maior relevo e prioridade no leque de ações estatais, em especial no terreno econômico e da inovação. Elas são acessórias, uma vez que o esforço decisivo sempre é de ordem interna, mas podem ser relevantes em cenários globais como os de hoje.

Cabe estabelecer desde já uma distinção entre diplomacia, política externa e política internacional, muitas vezes colocadas num mesmo patamar, como se fossem perfeitos equivalentes, quando na verdade respondem a dimensões diferentes das políticas públicas. A diplomacia é mera técnica, uma ferramenta, usada por todos os Estados - ou até mesmo por empresas, ou organizações não governamentais -, com vistas a atingir determinados objetivos em sua interface externa, para apoiar sua presença no cenário internacional. A política externa, por sua vez, consiste na formulação de objetivos específicos para tal ação, com base em valores e princípios - até constitucionalizados, como, no caso do Brasil, o artigo $4^{\circ}$ da CF-1988 -, cuja implementação prática, pela agência encarregada dessa política pública - no caso do Brasil, o Itamaraty, mas não só ele -, deve levar em conta um programa de atuação externa formulado por quem de direito: o presidente nos regimes 
presidencialistas, o chefe de gabinete e seu ministro setorial, nos sistemas parlamentaristas.

A política internacional, enfim, intervém nos ambientes global, regional ou bilateral, nos quais atuam de modo diferenciado os países, mas invariavelmente dotados de uma política externa e sustentados pelos seus representantes setoriais, os diplomatas de carreira, ou chefes ad hoc de missões especiais. As relações internacionais abarcam todas essas dimensões e as unem entre si. Feitas essas distinções, caberia agora discutir qual poderia ser a atuação externa ideal do Brasil, no quadro de suas políticas setoriais, suscetível de retirá-lo da lamentável condição descrita ao início, para colocá-lo de novo num patamar de crescimento sustentado, compatível com sua história passada.

\section{QUAIS SERIAM AS INSUFICIÊNCIAS DETECTADAS NA INTERFACE EXTERNA DO BRASIL?}

O Brasil, cabe deixar claro, não possui nenhum problema de política externa, ou sequer de diplomacia. Esta última está bem servida por um corpo de funcionários competentes, profissionais devotados disciplinadamente à política externa determinada pelo presidente e pelo ministro encarregado do Itamaraty. A política externa expressa, por sua vez, a orientação do chefe de Estado, e ela pode corresponder às mais sensatas posturas, como foi o caso tradicionalmente até 2002, por exemplo, ou então se deixar levar por preferências ideológicas "bizarras", como tivemos durante o período do lulopetismo diplomático, que conseguiu inflexionar a área internacional do país, a sua política externa e até a sua diplomacia, com interferências partidárias em todas elas.

Todos os diplomatas aprendem, no Instituto Rio Branco, a 
Relações econômicas internacionais: o Brasil na globalização

famosa frase do seu patrono, ao assumir a chefia da chancelaria, em 1902, depois de longuíssima estada no exterior: "Não vim servir a partidos, mas ao Brasil." Parece que não foi o caso nos anos de demagogia econômica e diplomática: além da recessão e do grave descalabro fiscal, os retrocessos no plano externo deveram-se justamente à miopia registrada nessa área.

A maior crise econômica de toda a nossa história foi indevidamente atribuída pelo regime lulopetista a uma suposta crise internacional, o que contraria as evidências disponíveis, já que países com o mesmo perfil de inserção internacional - exportação de commodities, baixa competitividade nos produtos de maior elasticidade-renda - fizeram bem melhor que o Brasil em termos de crescimento. Uma preferência atávica por um inexistente "Sul global" fizeram o Brasil perder grandes oportunidades comerciais, ao mesmo tempo que o seu entranhado protecionismo industrial - agrícola também - mantém o Brasil afastado das principais cadeias globais de valor, que constituem a face mais evidente do atual estágio da economia mundial e do comércio internacional.

É a política externa, portanto, que precisa mudar, sobretudo em sua vertente econômica, para que a diplomacia possa contribuir de modo competente e coadjuvante para uma solução aos maiores problemas da nação, que são, praticamente todos, de ordem exclusivamente interna. Com efeito, os mais graves problemas brasileiros - econômicos, políticos, sociais, regionais - têm origem interna e precisam receber soluções essencialmente, senão totalmente, domésticas, para que o Brasil possa iniciar um novo processo de crescimento sustentado, com transformações estruturais de seu sistema produtivo - no sentido de maiores ganhos de produtividade - e com a distribuição social de seus benefícios, mas esta preferencialmente por meio de mecanismos de mercado, antes do que pela via ilusória do distributivismo estatal. 
Não há muito o que a diplomacia ou a política externa possam fazer para resolver a grave crise fiscal que o país atravessa, e atravessará pelos próximos anos. Mas existe, sim, espaço para que ambas possam ser mobilizadas em favor do segundo grande problema da presente conjuntura histórica: a elevação dos níveis medíocres de produtividade. A diplomacia sempre foi a coadjuvante dos processos e programas nacionais de desenvolvimento, mas nem sempre ela foi orientada da maneira mais racional possível para servir plenamente a tais objetivos. Isto se deveu a equívocos da própria política econômica, em suas vertentes setoriais - a comercial, a industrial, a científica e tecnológica, a educacional, e outras mais sem deixar de mencionar o caráter errático das políticas macroeconômicas: cambial, fiscal e monetária.

\section{QUAIS PROBLEMAS, QUAIS SOLUÇÕES? QUAL O PAPEL DA POLÍTICA EXTERNA?}

A primeira tarefa da política externa, e consequentemente também a de sua diplomacia, é contribuir para um processo de crescimento sustentado dos ganhos de produtividade, pela redução do custo do capital e o aperfeiçoamento do capital humano, os dois elementos mais importantes da produtividade total de fatores, junto com as demais externalidades positivas que cabem ao Estado prover de forma eficiente. A melhor maneira de atingir esses objetivos passa pela abertura econômica e pela liberalização comercial; ambas medidas constituem, principalmente, decisões de política doméstica, bem mais do que de política externa, que é acessória a esses objetivos maiores. A maneira de fazê-lo é uma tarefa de política econômica interna, tanto por razões estruturais quanto conjunturais, e é fácil identificar as razões.

O Brasil, como afirmado, é um país introvertido, o mais fechado do G-20, o grupo de nações economicamente mais 
Relações econômicas internacionais: o Brasil na globalização

importantes do mundo, que todas possuem coeficientes de abertura externa bem superiores ao do Brasil. Ou seja, somos nós que estamos errados, somos nós que nos fechamos ao mundo, que condenamos nosso povo a consumir produtos caros e de baixa qualidade, que obrigamos os empresários a se abastecer internamente a custos bem mais altos. Isso os torna pouco competitivos externamente e redundou nessa desindustrialização precoce dos últimos anos.

No plano conjuntural, o mundo atravessa uma fase de relativa estagnação nas iniciativas e propostas de negociações comerciais multilaterais, e não há muito o que esperar da OMC, daí os muitos acordos de livre comércio em escala regional, ou dos esquemas mais abrangentes do que as zonas de comércio preferencial, restritos aos países dispostos a ir além dos meros mecanismos de acesso à mercados para entrar no terreno regulatório e nos novos temas dos intercâmbios globais (investimentos, serviços, propriedade intelectual, etc.). O Brasil, como no caso da abertura tarifária, está ausente desse universo negociador, e esse é o primeiro grande problema externo da fase atual.

Abertura econômica e liberalização comercial constituem, portanto, dois grandes objetivos de política doméstica que precisam e devem ser coadjuvados pela política externa e pela diplomacia para produzirem resultados benéficos no curto e no médio prazo. Foram esses dois elementos que contribuíram, junto com as privatizações, para maiores ganhos de produtividade na economia nos anos 1990, quando reformas foram feitas nessa direção, o que preparou o Brasil, a partir da estabilização macroeconômica conduzida entre 1994 e 1999, para a fase de maior crescimento na primeira metade dos anos 2000, expansão revertida e desmantelada logo adiante pelas políticas equivocadas adotadas a partir de 2006 e agravadas entre 2011 e 2015.

É nesse contexto de reformas estruturais importantes, a serem implementadas nos planos interno e externo, que se situa a 
importante decisão tomada em 2017 no sentido de solicitar a adesão plena do Brasil à OCDE, o "clube das boas práticas" que pode contribuir para esse processo de reformas que o Brasil deve perseguir no seu próprio interesse nacional. A OCDE possui notória expertise e vasta experiência nos terrenos das reformas fiscais, setoriais e sociais, com destaque para as áreas de políticas comercial, industrial, tecnológica e educacional, ou seja, tudo o que o Brasil necessita para deslanchar um novo salto no plano do crescimento sustentado. Os requerimentos de entrada podem, aliás, apoiar as reformas.

As reformas mais difíceis são, sem dúvida alguma, a fiscal e a tributária, uma conectada à outra, mas aqui também o know-how acumulado pela OCDE nessa área pode se revelar valioso, em várias dimensões. Na política comercial, os estudos da OCDE já provaram fartamente que restrições a um comércio mais livre redundam sempre num declínio da produtividade do trabalho, e portanto dos padrões de vida. O protecionismo comercial brasileiro dificulta, e de fato impede, uma maior integração de nossas empresas às cadeias globais de valor, que constituem o lado mais conspícuo da globalização microeconômica, que é onde se processa, junto com as ferramentas de comunicação social, o lado mais relevante desse fenômeno abrangente e inescapável.

A redução do custo do capital também passa por maior abertura econômica e basicamente pela maior atratividade de investimentos diretos, inclusive no setor financeiro, para diminuir o grau absurdo de concentração bancária hoje existente. A política externa e a diplomacia devem servir a todos esses objetivos da maneira mais eficiente possível, o que justificaria um redimensionamento da rede exterior de representação, exageradamente estendida na primeira década do presente século.

A política externa brasileira sempre teve como princípio organizador uma mal definida "diplomacia do desenvolvimento". 
Relações econômicas internacionais: o Brasil na globalização

Tratava-se, na verdade, mais de um slogan e, mesmo, uma ideologia, do que propriamente uma doutrina adequadamente elaborada, resultando de uma combinação improvisada de prescrições vagamente influenciadas pelo desenvolvimentismo latino-americano da CEPAL e de demandas de tratamento preferencial e mais favorável para países em desenvolvimento emanadas da UNCTAD. Ao abrigo dessas correntes de pensamento, ocorriam vibrantes discursos defendendo "espaços de políticas econômicas" em prol de "projetos nacionais de desenvolvimento", o que servia de razão, de justificativa e de defesa para o protecionismo tarifário, para as restrições aos investimentos estrangeiros em determinados setores, para os monopólios estatais em indústrias ditas "estratégicas", para restrições aos fluxos de bens, de serviços e de capitais em nome do equilíbrio do balanço de pagamentos, da preservação da autonomia tecnológica, ademais de diversos outros expedientes, mal coordenados entre si, mas que de fato atuaram contrariamente ao grande objetivo pretendido, que era o de romper a barreira do subdesenvolvimento para alcançar o patamar das nações ricas.

O Brasil não esteve sozinho nesses experimentos desenvolvimentistas, já que acompanhamos os mesmos tipos de políticas da maioria dos países latino-americanos, que, se bem sucedidas em sua implementação reiterada e teimosa ao longo de décadas, deveriam levar o continente àquele grande objetivo. Ora, o que se assistiu, ao longo do período, foi a superação gradual dos países latino-americanos pelos da Ásia Pacífico, praticamente uma troca de lugares na economia mundial, tanto em termos de pautas exportadoras, de diversificação industrial, de ofertas competitivas em bens e serviços, quanto da atração de investimentos diretos estrangeiros. A América Latina, e com ela o Brasil, reduziu seus índices de participação nos intercâmbios mundiais, ao passo que os países da Ásia Pacífico começaram a ocupar frações crescentes desses fluxos globais. 
Está, portanto, mais do que na hora de substituir essa mal definida "diplomacia do desenvolvimento com preservação da autonomia nacional” por uma vigorosa política de integração à economia mundial, com a adoção consequente de políticas setoriais visando à inserção das empresas brasileiras nos padrões competitivos da globalização. A OCDE poderá subsidiar a redefinição dessas políticas no novo sentido pretendido; mesmo quando a adesão formal não se realize, nada deveria impedir o Brasil de reformar o conjunto de políticas nas áreas industrial, comercial e tecnológica na direção da integração mundial, abandonando o prejudicial nacionalismo autonomista, que é de fato redutor de nossas possibilidades de progresso econômico.

\section{QUAIS SERIAM AS PRIORIDADES NOS PRÓXIMOS} ANOS?

O Brasil sempre privilegiou a via multilateral e a coordenação regional em diversas áreas, inclusive em matéria de integração econômica. Sob a diplomacia partidária do regime anterior ele fez mais do que isso: adotou preventivamente uma preferência ideológica por certas “parcerias estratégicas”, o que o fez perder tempo na busca de uma ilusória aliança com protagonistas do chamado "Sul global", o que podia encantar acadêmicos e militantes alheios às realidades da economia mundial, mas que em nada serviu para promover os interesses concretos de sua economia. O que caberia fazer doravante seria recuperar a plena autonomia da política externa na coordenação das políticas nacionais em todas as áreas de negociações internacionais e regionais, sem mais preferências ideológicas ou compromissos herdados do passado recente, que nos prendiam a determinados compromissos políticos mais estabelecidos em função daquelas preferências partidárias do que das reais necessidades da economia nacional. 
Relações econômicas internacionais: o Brasil na globalização

O Brasil é grande o suficiente, e dotado de uma diplomacia adequadamente preparada, para atuar de modo independente nos mais diferentes foros de negociações internacionais, sem precisar de uma coordenação redutora em certas áreas, o que o acaba levando a um mínimo denominador, em escala regional ou em outras esferas, distante, portanto, de objetivos mais ambiciosos, que correspondem ao seu novo objetivo de integração plena à economia mundial. $\mathrm{O}$ objetivo é este: a diplomacia deve atuar, o mais possível, de modo corajosamente autônomo, o que pode parecer óbvio, mas nem sempre prevalece, segundo concepções que privilegiam a ação via grupos.

A plena capacitação tecnológica de sua economia, por exemplo, pode e deve-se fazer numa abertura decisiva em direção dos parceiros tradicionais do passado, do que numa ilusória aliança com novos parceiros, ditos "não hegemônicos", dessa aliança geograficamente determinada numa única direção. Da mesma forma, políticas sociais e educacionais, ou mesmo a regulação setorial, ganhariam bem mais com a adoção de padrões já adequadamente testados em países avançados, todos pertencentes à OCDE, do que nesses experimentos duvidosos, empurrados burocraticamente por tecnocratas descolados da vida empresarial, ou penosamente e artificialmente estimulados num âmbito puramente dominado pela tecnocracia governamental.

\section{QUAIS SÃO OS RECURSOS DISPONÍVEIS PARA OS PROGRESSOS NA ÁREA EXTERNA?}

Qualquer consulta aos relatórios técnicos mais relevantes da economia global - competitividade, ambiente de negócios e liberdade econômica - revela que o Brasil não avançou, e que, de 
fato, ele recuou em vários desses indicadores globais ou setoriais, o que foi o resultado de anos de inépcia administrativa e de incompetência gerencial, o que cabe agora corrigir e avançar, para recuperar o atraso acumulado.

O que se propõe, portanto, é a adoção verdadeiramente estratégica de todos esses indicadores, refinados e adaptados ao nosso contexto, para guiar as diretrizes setoriais da política externa e da diplomacia brasileira nesse esforço de integração do Brasil à economia global. Os relatórios anuais do Fórum Econômico Mundial sobre competitividade, os do Banco Mundial sobre "Fazendo Negócios" e os do Fraser Institute sobre liberdades econômicas deveriam converter-se em manuais práticos de nossos técnicos econômicos e diplomatas na redefinição de amplas áreas da regulação nacional tratando de políticas econômicas externas e de relações econômicas internacionais. Uma leitura atenta desses relatórios, confrontando indicadores relativos ao Brasil com os de outros países, inclusive economias menores ou nações de menor renda per capita que a brasileira, revela o que já se sabe: nosso país apresenta inúmeras distorções macro e setoriais, quase todas elas derivadas da burocracia estatal, de um sistema tributário extorsivo e irracional, de uma regulação intrusiva, tudo isso fazendo um ambiente de negócios verdadeiramente infernal para o empresário nacional.

Deve-se, aliás, corrigir essa noção de que existe um "custo Brasil", o que tornaria o cenário em algo quase determinista, ou fatalista, como se a responsabilidade fosse de todos, ou seja, de ninguém. Na verdade, esse custo deve ser chamado pelo seu verdadeiro nome: custo do Estado brasileiro. É ele o grande responsável por uma carga fiscal equivalente à média dos países ricos, numa economia com um PIB per capita cinco vezes menor, ou seja, um nível tributário mais de dez pontos percentuais acima dos países emergentes de renda equivalente. Não apenas o volume de 
Relações econômicas internacionais: o Brasil na globalização

impostos é avassalador para a competitividade das empresas brasileiras, mas a burocracia envolvida no recolhimento dessas receitas compulsórias é, também, estupidamente esquizofrênica.

Todos esses relatórios exibem um número tão excessivo de idiossincrasias - não necessariamente brasileiras, mas do Estado brasileiro, e dos seus governos - que a nossa diplomacia pode passar um bom tempo identificando como os outros países colocados num mesmo patamar de desenvolvimento atuam sobre os mecanismos mais distorcivos e mais perversos que retiram competitividade aos produtos e serviços aqui produzidos e que colocam o Brasil nos piores indicadores em escala comparativa. A Índia, por exemplo, deu enormes saltos de produtividade e de competitividade no plano mundial simplesmente ao identificar os critérios no levantamento do Banco Mundial que a colocavam numa classificação muito baixa no ranking do Doing Business: o trabalho feito de correção dessas distorções levou-a, em poucos anos, a ultrapassar o Brasil na classificação geral. O mesmo pode ser feito pela diplomacia brasileira em diversos outros componentes de políticas setoriais, identificando as melhores práticas pelos países que apresentam indicadores mais favoráveis ao ambiente de negócios.

A redução eventual das receitas, advinda de reformas no sistema tributário e nos mecanismos regulatórios, seria mais do que compensada pelos ganhos de produtividade e de competitividade a serem incorporados pelas empresas brasileiras em decorrência dessa adequação a patamares "normais" de funcionamento do sistema produtivos, em todo caso segundo padrões vigentes na maioria dos países inseridos na economia global. É evidente que haverá custos de transição, que terão de ser compensados pela redução das despesas públicas, mas neste campo também a diplomacia precisa ser mobilizada para demonstrar as imensas distorções existentes sob a forma de gastos com o próprio Estado e seus aparelhos institucionais, quando vistos em escala comparativa. Parece claro, por exemplo, que 
o funcionamento dos poderes, a remuneração da sua burocracia, o custo da Justiça do Trabalho e, sobretudo, dos regimes previdenciários constituem verdadeiras anomalias vistas no plano internacional, e isso precisa ser evidenciado pela nossa diplomacia, em função de sua capacidade de realizar levantamentos de questões funcionalmente similares em direção de países com instituições equivalentes.

O mesmo se estende, por exemplo, aos mercados de capitais, regimes laborais, sistemas de inovação, funcionamento do ensino público e sua complementação pelo setor privado nos diversos níveis e várias outras áreas problemáticas no atual cenário brasileiro: a diplomacia pode, e deve, trazer uma grande contribuição para diagnósticos realistas sobre as disfunções brasileiras, atribuindo-se depois à política externa a missão de negociar eventuais acordos de cooperação para que as prescrições adequadas sejam seguidas de propostas concretas de reformas setoriais, em linha com padrões existentes de qualidade em países de melhor desempenho nessas áreas. Aqui, novamente, a OCDE poderia prover o Brasil de todas as informações necessárias a esses diagnósticos.

\section{COM QUEM PODEMOS CONTAR? RELAÇÕES REGIONAIS E COM GRANDES PARCEIROS}

A primeira circunstância do Brasil é, obviamente, a sua geografia, e é com ela que o país deve trabalhar para assegurar um ambiente continental favorável ao bem-estar dos seus povos, aos processos de desenvolvimento, à segurança e ao respeito aos princípios dos direitos humanos e da democracia inscritos em nossa Constituição. Nela também está a "obrigação" de realizar a integração com as demais nações da região. O projeto de integração - que já passou por diversas fases - necessita porém ser retomado em novas 
Relações econômicas internacionais: o Brasil na globalização

bases, uma vez que a união aduaneira do Mercosul não parece ter condições de funcionar de modo adequado na configuração atual. De certo modo, o Brasil, como o país mais avançado industrialmente e tecnologicamente, pode decidir abrir-se de modo mais amplo aos produtos e serviços dos países vizinhos, sem exigir reciprocidade. Caberia, igualmente, retomar o projeto de integração física proposto em 2000 e deixado num estado disfuncional pelos equívocos de política econômica e de política externa, nos anos em que esta foi dominada por uma diplomacia partidária animada mais por preconceitos ideológicos do que pela expressão concreta dos interesses nacionais.

Muito do que deve ser feito no continente nesse terreno depende, obviamente, de um bom ambiente regulatório, o que pode revelar-se praticamente impossível quando vários países adotaram orientações estatizantes e contrárias ao investimento estrangeiro em suas disposições setoriais nacionais, aliás, como o próprio Brasil durante o reinado companheiro. Assim, a mudança de postura do Brasil nessas áreas, sobretudo a abertura necessária aos capitais internacionais, pode sinalizar um bom ambiente de negócios e de investimentos, que cabe estimular nos planos da diplomacia e da política externa por novas iniciativas de caráter integracionista pragmático. Aqui, como em vários outros terrenos, os problemas são e continuam a ser de ordem essencialmente interna - como é o caso do protecionismo brasileiro, mesmo contra produtos e serviços dos vizinhos que, teoricamente ao menos, gozam de acesso aos mercados brasileiros por mera redução das tarifas aplicadas, quando os problemas são propriamente regulatórios -, o que, porém, não deveria impedir a diplomacia de indicar claramente quais os obstáculos percebidos por esses países. Ao proceder em modo de abertura unilateral, o Brasil pode contribuir para a formação de um grande espaço econômico integrado em escala regional, sem mesmo precisar negociar acordos bilaterais ou plurilaterais com os países vizinhos. 
Por outro lado, o conceito de "parceria estratégica" foi usado de modo muito peculiar nos anos do lulopetismo diplomático, privilegiando unilateralmente supostos aliados considerados "antihegemônicos", numa tentativa canhestra de criar "novos polos de poder" distanciados das antigas potências coloniais e "imperialistas". Na verdade, a diplomacia brasileira não precisa e não deveria ficar selecionando quais são ou deveriam ser os seus "parceiros estratégicos". O que uma política externa sensata deve fazer, a partir de claras diretrizes governamentais, é definir quais são os objetivos estratégicos nacionais, suas metas prioritárias, e a partir daí, e em função disso, escolher as melhores parcerias que se encaixem de forma racional e pragmática na perspectiva da cooperação ideal para os setores e áreas nas quais se busca o melhor desempenho para aquele campo específico. Não existe e não pode existir um determinismo geográfico por um fantasmagórico "Sul global” em todas as áreas de interesse brasileiro de cooperação, assim como não podem existir grupos rígidos e coalizões estáveis, quando são muito diversos os objetivos estratégicos do país: o interesse nacional deve, assim, selecionar os melhores parceiros, não aqueles supostamente alinhados ideologicamente.

\section{AS BARREIRAS EXISTENTES, AS VEREDAS DO PROGRESSO E O ENGAJAMENTO DECISIVO}

Mais do que obstáculos materiais intransponíveis, as barreiras existentes a um processo sustentado de crescimento econômico se situam em alguns dos "ismos" já detectados muitos anos atrás por alguns dos melhores estadistas brasileiros: o dirigismo e o intervencionismo estatais, o protecionismo exacerbado, o nacionalismo equivocado e o patrimonialismo entranhado em nosso sistema político. A diplomacia brasileira é perfeitamente capaz de 
Relações econômicas internacionais: o Brasil na globalização

colocar o Brasil numa perspectiva comparativa internacional, evidenciando nossas mais graves limitações em termos de custo do capital, de ambiente de negócios e de ganhos de produtividade. Podese, por exemplo, tomar como guias o relatório do Banco Mundial sobre ambiente de negócios, o do World Economic Forum sobre competitividade e o do Fraser Institute sobre liberdades econômicas, e também os dados da OCDE sobre deficiências educacionais, que incidem sobre a produtividade do capital humano, para, a partir daí, identificar claramente quais políticas setoriais e quais medidas adotar para colocar o Brasil no cenário global. A intenção seria fornecer um roteiro sobre onde, como e em que ritmo trabalhar para superar as limitações setoriais, sendo que a análise internacional teria de ser intensamente confrontada aos dados internos e, sobretudo, ao ambiente regulatório nacional, para verificar e identificar uma agenda de reformas.

O Itamaraty poderia ser mobilizado nessa nova frente de trabalho para pesquisar, pensar e propor reformas fundamentais no plano interno, com base numa análise qualitativa (mas apoiada em sólidos dados quantitativos) dos dados internacionais com respeito às políticas e instituições de maior eficiência relativa em três áreas fundamentais para o bom desempenho do país: Justiça, Trabalho e Educação. Alguns dos dados a respeito dessas questões setoriais mas que são, ao mesmo tempo, políticas horizontais e de caráter praticamente macro, ainda que incidindo sobre cada uma dessas instituições no plano do seu funcionamento micro - já estão presentes nos relatórios acima referidos, mas um trabalho de pesquisa suplementar precisa ser conduzido para isolar fatores, mecanismos e instrumentos que atuam para dar maior eficiência na condução desses setores nos países que apresentam boas performances.

A intenção não seria fazer com que o Brasil copie modelos estrangeiros ou adote estruturas e instituições moldadas para outros 
contextos sociais e culturais, mas identificar nossas deficiências relativas - em alguns casos absolutas - e fazer as reformas adaptativas necessárias para aumentar o grau de eficiência no funcionamento desses importantes setores da vida pública. Por acaso se trata de três áreas nas quais comportamentos corporativos, deformações patrimonialistas e resistência às reformas são mais entranhados, exigindo, por isso mesmo, uma demonstração cabal de como o Brasil destoa dos exemplos de maior eficiência setorial, para justificar e defender a necessidade de reformas nessas áreas. O que se pode desde já antever é que reformas nessas áreas superam um mandato governativo e que elas devem ser vistos como um processo de adaptações contínuas aos dados sempre cambiantes da realidade.

Estudos setoriais complementares precisariam igualmente ser conduzidos para outras importantes questões de interesse nacional relevante, como o sistema tributário e as instituições e medidas de segurança pública, mas cuja complexidade supera, provavelmente, a capacidade analítica do Itamaraty, que pode, no entanto, ajudar a identificar as melhores práticas em outros contextos nacionais, em cooperação com os órgãos pertinentes do Brasil, que de toda forma já possuem assessorias internacionais.

A política externa e a diplomacia brasileira sempre foram esteios fundamentais em fases anteriores do processo de desenvolvimento nacional. No entanto, as políticas macro e setoriais adotadas, sobretudo no período recente, padeceram dos defeitos já apontados aqui: introversão, protecionismo, nacionalismo excessivo, dirigismo mal concebido e mal implementado. Uma reorientação geral dessas políticas, no sentido da abertura econômica e da liberalização comercial, fará com que a política externa e a sua diplomacia voltem a atuar como suportes essenciais, ainda que complementares, a um novo tipo de desenvolvimento. 
Relações econômicas internacionais: o Brasil na globalização

Data de Submissão: 09/07/2018

Data de Aprovação: 13/07/2018 Processo de Avaliação: desk review

Editor Geral: Jailton Macena de Araújo

Editor de Área: Maria Creusa de Araújo Borges 